\title{
EN DIÁLOGO CON VICO
}

\section{Alessandro Stile (ISPF, del CNR)}

RESUMEN: El texto constituye el extracto de una "entrevista a Vico", aún inédita, imaginaria pero rigurosamente basada en textos viquianos, a la que solamente se le han añadido las necesarias modernizaciones lingüísticas. Palabras ClaVe: Vico, $350^{\circ}$ Aniversario, método de los estudios, ciencias naturales, enseñanza universitaria, verdad, sentido común, verosímil, fantasía, tópica, A. Stile.

\section{In dialogue with Vico}

ABSTRACT: This text is an extract of an "interview with Vico", still unpublished, imaginary but rigorously based on Vichian texts, to which only the necessary linguistic modernizations have been added.

KEYWORDS: Vico, 350 th Anniversary, method of studies, natural sciences, university education, truth, common sense, credible, fantasy, topical, A. Stile.

\section{In dialogo con Vico}

RIASSUNTO: Il presente testo è l'estratto di un "colloquio con Vico", tuttavia inedito, immaginario ma rigorosamente basato su testi viquiani, a cui sono state aggiunte solo alcune necessarie modernizzazioni linguistiche.

PAROLE CHIAVE: Vico, $350^{\circ}$ Anniversario, metodo degli studi, scienze naturali, insegnamento universitario, verità, senso comune, verosimile, fantasia, topica, A. Stile.

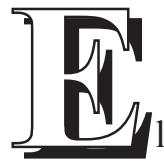

texto propuesto aquí no constituye, más allá de la banal distancia factual-temporal, una "entrevista imposible", porque el encuentro -que todo estudioso tiene con el propio Autor, para repensarlo después y elaborarlo con autonomía-, en este caso afronta los textos de Vico de forma rigurosa, sin alejarse mínimamente de sus palabras, salvo por alguna obligada modernización. La entrevista completa todavía permanece inédita y será utilizada para una representación teatral en el ámbito de las celebraciones por los 350 años del Filósofo. El fragmento extractado aquí se refiere específicamente a la relación de Vico con la modernidad y con los jóvenes: dos temas de absoluta contemporaneidad. 
Giambattista Vico no es un personaje simple, y esta entrevista, que puede parecer desenvuelta y lineal, en realidad nos ha costado mucho. De entrada, empezando por el tiempo y el lugar de nuestro encuentro: tras un primer intento, por la mañana, fallido por el vocerío increíble que provenía tanto del interior de la casa (una caterva de hijos) como de las calles del centro histórico donde se encontraba este apartamento, pequeño y anónimo, se decidió que nos encontrásemos por la noche, cuando los estrépitos se disuelven, y el Profesor parece tener una segunda vida, sumergido como está entre libros totalmente anotados, entre apuntes esparcidos, entre cartas sin terminar aún, que sustituyen la algarabía del día mundano por el lenguaje de la cultura con el que se encuentra verdaderamente a gusto. Y aquí, pues, en una noche de primavera, fui recibido, y tomé apuntes sobre el río de palabras de mi ilustre huésped. Pero no bastó para organizar la entrevista: quiso revisar todo lo que yo había transcrito, cerciorándose de que hubiese referido sus palabras de modo literal, permitiéndome solo ablandar un lenguaje que le confesé que era inaceptable para los oyentes de hoy. Tuvo dificultades para entenderlo, y se limitó finalmente a estallar, como hace a menudo, consintiendo.

- Profesor, tiene usted un extraño carácter, puedo decirlo, por lo que he captado en estos días. Sabe divertirse también, pero se muestra con frecuencia sombrio, se ofusca y tiene repentinos ataques de ira de los que se arrepiente también de golpe. ¿Siempre ha sido asi?

- De niño, me dicen, era muy alegre y nunca me estaba quieto. Después, cuando tenía siete años, me caí de una escalera y permanecí mucho tiempo entre la vida y la muerte; el médico dijo que la alternativa a la muerte sería la demencia. Dios quiso que no fuese así; pero desde entonces crecí melancólico y poco sociable. Pero quizá sea esta la naturaleza de los hombres que quieren buscar, que quieren poner en valor su ingenio y que no quieren plegar el razonamiento a las cosas superficiales y falsas.

- Vayamos enseguida a algunos puntos importantes de su pensamiento. Usted es particularmente critico con el modo en que se estudia hoy. Naturalmente, se refiere a un hoy muy alejado de nosotros, hace trescientos años; sin embargo, ya hemos hablado de ello, existen preocupaciones comunes...

- Lo que me parece más grave del método empleado en el estudio y en la investigación es que dedicamos el máximo empeño a la ciencia, pero no prestamos la misma atención a las ciencias morales. Estoy hablando de toda esa esfera del conocimiento que se refiere específicamente al alma y a las pasiones; estoy hablando de las cualidades que existen en cada uno, de los vicios, del modo con el que sería necesario afrontar la vida práctica; estoy hablando de una atención específica a los problemas ligados a la edad, al sexo, a las condiciones sociales, a las pertenencias étnicas. Hoy, el estudio está orientado únicamente a la verdad: bien, pero este 
objetivo hace apuntar rápidamente a la investigación científica porque parece incontrovertible, y no a la naturaleza del hombre, que para ser individualmente libre deviene muy difícil de aferrar. Entonces, esta impostación tiene un doble inconveniente por cuanto respecta a los jóvenes: los hace actuar sin prudencia en la sociedad, y al mismo tiempo los limita en la expresión, impide otorgar a su modo de argumentar una valencia intensa y efectiva.

- Y siempre ha sido muy crítico con un cierto modo de "servirse" de la ciencia...

- Sí, porque es erróneo aplicar a la vida cotidiana los mismos criterios usados por la ciencia. Los científicos consideran las cosas con una racionalidad que definen como "rectilínea", mientras que los hombres, que de hecho son limitados, estúpidos y demás, se dejan guiar por las pasiones, por las circunstancias en las que se encuentran. Los científicos, al evaluar las cosas humanas las ven como deberían ser, pero los hechos a menudo siguen trayectorias diversas y misteriosas. Diré más: quien juzga según los criterios de la ciencia y ostenta la "verdad" no tiene en cuenta lo que los hombres sienten respecto a la verdad, o el hecho de que incluso ignoran el sentido de la verdad.

- Corríjame si me equivoco: está diciendo que los objetivos de la ciencia, pero presumo en este punto, también los de una cierta filosofía, son legítimos, pero que es preciso contar con una realidad de hecho que reclama otros parámetros; el otro día me puso el ejemplo de una medida de plomo de la que decía Aristóteles que, en lugar de constreñir los cuerpos a aquella medida se adapta a los cuerpos mismos...

- Viviendo en una sociedad es preciso considerar que los comportamientos del hombre se mueven entre ocasiones y elecciones, ambas inciertas, donde dominan la simulación y el disimulo. Ahora bien, quienes se ocupan exclusivamente de la verdad se confunden, y difícilmente consiguen valerse de los medios, y aún más difícilmente llegan a conseguir sus fines; por lo cual, frustrados en sus propósitos, engañados por sugerencias de otros, muy a menudo renuncian y abandonan el compromiso social. Por ello, visto que las acciones de la vida práctica resultan valoradas sobre la base de las situaciones y de las consecuencias, es decir, sobre la base de las circunstancias, y que muchas acciones parecen incongruentes y sin significado -aparte de desconcertantes por donde van a parar-, no se puede evaluar el factor humano con una norma de la mente rectilínea y rígida.

- Usted que ha enseñado en nuestro Ateneo, ¿no cree que esta toma de conciencia debería competer particularmente a los estudios universitarios?

- Hoy tenemos la fortuna de tener una Universidad donde se enseña todo tipo de disciplinas con docentes especialistas en cada materia. Pero he aquí el problema: las actividades prácticas y las ciencias que hace un tiempo la filosofía encerraba en sí mismas de forma unitaria, están hoy divididas y separadas. En la anti- 
güedad los filósofos no solo vivían de conformidad con las doctrinas que enseñaban, sino que además se servían de un método de exposición adecuado. Hoy la enseñanza está confiada a docentes competentes en las materias que enseñan, pero acaba siendo de tal manera fragmentaria e incoherente, que a una materia específica no le corresponde un conocimiento del conjunto; lo que a mi parecer representa la joya de la corona de la cultura.

- Perdóneme si insisto, pero este es un punto muy discutido todavía hoy: ¿usted es favorable o no al pensamiento moderno? Hablamos naturalmente del cambio del cual en el siglo XVII el pensamiento de Descartes se hizo portavoz.

- El cartesianismo propuso una fórmula, cogito ergo sum, según la cual, incluso cuando se duda, se tiene la certeza del hecho mismo de pensar. De este modo, el escepticismo, que duda de todo, parecería verdaderamente derrotado. Además, el álgebra, que Descartes aplicó a la geometría, resuelve con soluciones brillantes esos problemas que los antiguos, que también se habían servido de la geometría y de la mecánica, no habían sabido resolver. En suma, aquí no se discute si la geometría y la nueva mecánica habían podido alcanzar un más alto grado de desarrollo por medio del álgebra. Los científicos, para no perderse en la ciencia de la naturaleza, introdujeron en física el método geométrico con el objetivo de describir las causas por las cuales esta maravillosa máquina del mundo fue ordenada por Dios. Hoy finalmente pueden proceder no a tientas como los físicos, sino como arquitectos de una extraordinaria construcción. Y podría continuar con la química, la anatomía, la astronomía...

- Parecería una apología del cartesianismo y de la ciencia moderna. ¿Y entonces?

- Es siempre la misma cuestión. Lo que yo sostengo es que el método con el cual el saber científico se afirma hoy tiende a suprimir otros elementos fundamentales que pertenecen al hombre. Hoy el punto de partida de todo estudio es el criterio cartesiano de la claridad y distinción. ¿Recuerda a Descartes? "no aceptar nunca cosa alguna por verdadera hasta que no se la reconozca evidentemente como tal". Esto significa que su criterio de verdad, para ser depurado no solo de toda falsedad, sino también de toda sospecha de falsedad, reclama que se aleje de la mente lo verosímil, ya que es considerado como falso. Lo explico enseguida: lo verosímil es cualquier cosa que está en medio entre lo verdadero y lo falso, pero es verdadero en la mayor parte de los casos. La actitud selectiva de la ciencia tiene consecuencias negativas, mientras que lo que en los adolescentes se debe formar muy rápido, y no obstaculizar, es lo que yo defino como "sentido común".

- Se lo ruego, explíquelo bien, porque en el lenguaje cotidiano el sentido común se identifica con el "buen sentido". ¿Se trata de esto?

- No exactamente: para mí significa un modo de sentir que pertenece a la humanidad entera; es gracias a este "sentido común" como los adolescentes se convierten en adultos, encuentran un criterio para su comportamiento práctico. Pertenece por naturaleza a los hombres de todas las naciones, y nació por separado 
en cada sociedad, sin que la una tuviese conocimiento de la otra. Solo a través de guerras, alianzas y comercios se convirtió en un "derecho natural" de todos los pueblos: ninguna ley lo ha impuesto. Por este motivo, a diferencia de otros, yo pienso que la naturaleza humana es sociable.

- Entiendo que estamos hablando de un criterio muy distinto de aquel sobre el que se fundamentan las ciencias...

- Sí, porque mientras que la ciencia nace de lo verdadero y el error nace de lo falso, el sentido común del que hablo nace, como ya he dicho, de lo verosímil. Justamente por esto, teniéndose que desarrollar el sentido común en los adolescentes, es de temer que el actual método con el que se busca la verdad acabe por sofocarlo. Quiero añadir además que el sentido común aparte de indicar el comportamiento a observar en el vivir civil, indica también un criterio para saber guiar la discusión. El peligro es que la que yo llamo "crítica", es decir, el método cartesiano, forme adolescentes que luego se encuentren en dificultades para saber argumentar.

- Usted se preocupa mucho por los jóvenes...

- Le ruego que me deje terminar, quiero decir otra cosa importante: el nuevo pensamiento, el rigorismo racionalista, sitúa la verdad fuera y más allá de toda imagen corpórea. Bien, no se puede discutir sobre esto, pero sí sobre el hecho de que lo enseñan a los adolescentes de forma totalmente prematura. La razón florece en la vejez, pero la adolescencia está totalmente llena de aquella fantasía que desde siempre caracteriza de la forma más bella a esa edad. Y vinculada a la fantasía aparece otra cualidad que es vivísima en los jóvenes, y que no se debe debilitar, esto es, el ingenio, la capacidad para observar las cosas e imitarlas, y que es capaz de aplicarse en todos los campos en los que la fantasía tenga un papel importante. Para acostumbrarse a la razón, en otros términos, los jóvenes tienen que formarse con las imágenes.

— ¿Qué es lo que puede contraponerse a los riesgos de este tipo de enseñanza?

- En primer lugar, lo que en el lenguaje de la retórica se llama "tópica", es decir, una especie de técnica con la que se inventan los argumentos dentro del discurso a analizar, y que viene antes que la "crítica", que es una técnica de evaluación. Sin embargo, los defensores del así llamado método crítico consideran la tópica inútil, porque sostienen que en el momento en el que se enseña una cosa se pueden ya concretar tanto los elementos de verdad como los de verosimilitud. Pero esta es la cuestión: ¿cómo hacerles ver a todos estos elementos?, ¿cómo hacer para captar toda la riqueza presente en un objeto del pensamiento? Naturalmente, es preciso ser cautos, porque también la tópica se expone a un riesgo, que es el de aceptar por verdadero lo que no es verdadero, así como los críticos no admiten lo verosímil porque lo consideran falso. Pienso, pues, que para evitar ambos riesgos es necesario que la formación de los jóvenes sea lo más completa posible: deben ante todo enriquecer su bagaje de experiencia con los "lugares" de la tópica; después que, sirviéndose del sentido común del que antes hablábamos, puedan exponerse al com- 
portamiento y a la argumentación; además, con la fantasía y la memoria deben dedicarse a aquellas actividades que se fundamentan sobre estas facultades de la mente. Solo en ese punto tiene sentido instruirlos en la crítica.

- Pero entonces, puede decirme, sin dar muchos rodeos, ¿qué piensa de Descartes?; que aún hoy está considerado como su gran adversario-porque es claramente a él a quien se refiere cuando critica el método de la ciencia de su tiempo-.

- Es preciso reconocer a Descartes el haber centrado en el sujeto el descubrimiento de la verdad, saliendo de una suerte de subordinación hacia el pasado. Y, además, es preciso reconocerle el haber querido instaurar un orden en el pensamiento, cuando el desorden reinaba indiscutible. Pero afirmar, como él hizo, que no reine otra cosa que el propio juicio y que el único método válido sea el geométrico, ¡me parece demasiado! Llegó a condenar el estudio del latín y del griego, lo que significa impedir alcanzar ese modo de pensar tan lleno de sabiduría de los romanos y aquel exacto y agudo de los griegos. Significa impedir rehacerse al derecho romano, que a su vez deriva de la cultura oriental. Significa renunciar a conocer las fuentes mismas de la religión. Condena la poesía, porque, a su entender, los poetas cuentan fábulas, sin comprender que las fábulas pueden acercarnos más que otra cosa a la verdad. En definitiva, este método acaba por hacerle el juego al escepticismo mismo, que tanto condenaba también Descartes, porque el escepticismo no encuentra nada mejor que atacar los estudios de historia, la poesía, las lenguas, todo lo que se fundamenta, en suma, en el sentido común y en lo verosímil.

- Esto no puede saberlo, pero usted ha sido señalado hace algunos años por el Ministerio de Instrucción como la figura más digna de representar la cultura en el Nápoles de su tiempo; y en este 2018 han sido muchas las iniciativas para celebrar su 350 cumpleaños, y también para darlo a conocer más a los jóvenes. Alguno ha objetado que dificilmente Giambattista Vico podría interesar a un "Genarito", a un chico cualquiera de hoy, porque su pensamiento es dificil y su lenguaje es a veces oscuro. ¿Cómo se posiciona respecto a estas observaciones?

- Tienen razón por lo que respecta a Vico. Pero el hecho es otro, y se refiere al padre, al profesor, al educador de Genarito, y lo que deben hacer por él. Nuestra alma tiene una riqueza que defino como divina, porque es divino ver, es divino sentir, es divino entender, es divino razonar, es divino recordar. Y, además, ¿no le parece divino el ingenio, la sagacidad, la agudeza, la perspicacia? Entonces yo digo: ¡Despertemos todas estas cualidades que están encerradas en nuestro ánimo desde siempre, como chispas enterradas, y suscitaremos en Genarito la llama del entusiasmo por todo el saber! Esto lo dice Vico, y solo esto puede darle gloria.

[Traducción del italiano por María José Rebollo Espinosa]

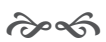

